\title{
Effects of transport operating conditions on the rating of OTOP products of small and medium- sized enterprises (SMEs) in Thailand
}

\author{
Pisit Potjanajaruwit ${ }^{1, *}$ \\ ${ }^{1}$ Suan Sunandha Rajabhat University, Bangkok, Thailand
}

\begin{abstract}
The purpose of this research was to explore the operating conditions of Small and Medium-sized Enterprises (SMEs) and their effects on the rating of products in Thailand's One Tambon One Product (OTOP) program. The sample group in the research was the 330 owners or executives of Small and Medium-sized Enterprises that produced for the OTOP program and their products were rated 3-5 stars. A questionnaire was used to collect data. The statistics used for data analysis were Percentage, Mean, Standard Deviation. Chi-Square, and one-way ANOVA, while Scheffe Analysis was used for multiple comparisons. The study found there were 19 operating conditions of the SME producers of OTOP program found affecting the rating of their 3-5 star products including; Marketing Operating Conditions - such as packaging, main target market, marketing promotion, Production Operating Conditions - such as production policy, production plan, standard certifications, raw material management, production methods, product development, member selection, production cost, Financial Operating Conditions - such as initial investment, working capital, working capital management model, main operational objectives, operational strategy, assignment of duties and responsibilities, employee performance indicators, and the member remuneration, which were all found statistically significant at the .05 level.
\end{abstract}

\section{Introduction}

One Tambon One Product Project (OTOP) is a governmental program that was designed by Thailand's former Prime Minister Thaksin Shinawatra, to bring prosperity to local communities by creating more jobs for local people, leading to a more stable and continuous income, and eventually self-reliance. This concept was inspired from the operation of Oita Prefecture, a province in the southern part of Kyushu, Japan, which focuses on making a social change in a way that their people will earn higher incomes through The Gross National Satisfaction Society instead of the Gross National Product, which is currently used. The Japanese program's focus is also put on productions that present their local wisdom to the world by producing and developing local products to be accepted internationally. The One District One Product Project is run based on 3 principles: First - "Local Yet Global" - Manufacturing of products and services using local wisdom

* Corresponding author: pisit.po@ssru.ac.th 
and culture to be internationally accepted. Second - "Self-Reliance-Creativity" - Making dreams come true by using OTOP processes to create activities that rely on the local potential. Third - "Human-Resource Development" - A promotion of a creative spirit in people for them to fight their way through life with determination and courage [1].

Dr. Suvit Maesincee, Acting Director of One Tambon One Product (OTOP) Project Coordination Office [2]. said that promotion of the OTOP products in the previous year was considered successful in pushing the product to be known in the international market. However, the result of the selection of the "Product Champion" of the same year revealed that - there were only $10 \%$ of the 5 -star OTOP products found to have satisfactory sales as most local manufacturers were faced with various problems, making them unable to have satisfactory sales of their products. Therefore, Mrs. Suchada Arunrakthavorn, an officer of the Department of Export Promotion in the Ministry of Commerce has summarized the past operating barriers for manufacturers as follows;

Table 1. Problems and obstacles in the past operations of OTOP producers [2].

\begin{tabular}{|l|l|}
\hline \multicolumn{1}{|c|}{ Type of SMEs } & Problems and obstacles in the past operations of OTOP producers \\
\hline & $\begin{array}{l}\text { 1. Lack of competitive capability } \\
\text { 2. Constant labor turnover }\end{array}$ \\
$\begin{array}{l}\text { 3. Most products are manufactured in the original forms and not } \\
\text { developed to be more modern. }\end{array}$ \\
$\begin{array}{ll}\text { 1. Manufacturing } & \text { 4. Uncertain product/service delivery time } \\
\text { 3. Wetail } & \text { 5. The pricing of the products is not standardized. } \\
\text { 4. Service } & \text { 6. Lack of product design ability. } \\
\text { 7. Slow response to the market } \\
\text { 8. Lack of dedicated marketing personnel } \\
\text { 9. Lack of networking, making it impossible to strengthen the business } \\
\text { operation } \\
\text { 10. Unable to produce the required quantity. }\end{array}$ \\
\hline
\end{tabular}

The aforementioned reasons led to this research study on the operating conditions that affect the rating of OTOP products of Small and Medium-sized Enterprises (SMEs) in Thailand. The study aimed to explore the operating conditions of Small and Medium-sized Enterprises (SMEs) producers that may affect the rating of OTOP products in Thailand. The results from this study should be useful in improving and developing potential of SME producers of OTOP products in Thailand and the operations of other organizations with similar operations.

\section{Methodology}

\subsection{Study Design}

This study is a survey research that explores the operating conditions that affect the rating of OTOP products of Small and Medium-sized Enterprises (SMEs) in Thailand. The methodology of this study is as follows;

\subsection{Determination of Population and Sample}

The population of this research was 2,356 business owners or executives of Small and Medium-sized Enterprise producers in the One Tambon One Product project whose products were selected for 3-5 ratings by the One Tambon One Product National Administrative Committee (ONAC) in 2019 (www.cdd. go.th, 2019). 
The sample size of this research was calculated using a sample size calculating program [3]. at $95 \%$ confidence level, $+5 \%$ error, which resulted in a total sample size of 330 people. The samples were selected using purposive sampling as the study required data specifically from 3-5 star-product business owners or executives of Small and Mediumsized Enterprises via the use of a survey questionnaire. The samples of these SME OTOP producers could be divided into; 110 SMEs with a 3-star rating: 110 SMEs with a 4-star rating, and 110 SMEs with a 5-star rating, making a total of 330 samples as shown in the table.

Table 2. Samples of Small and Medium-sized Enterprises, producers in the One Tambon One Product Project as classified by their product ratings from 3 to 5 stars.

\begin{tabular}{|c|c|}
\hline OTOP products' rating level & Sample group population number \\
\hline 3 stars & 110 \\
\hline 4 stars & 110 \\
\hline 5 stars & 110 \\
\hline Total & 330 \\
\hline
\end{tabular}

\subsection{Study tools}

The tool used in this research was a questionnaire created through studying of information from books, documents, articles, relevant research, as well as related interviews with experienced OTOP producers in order to guide the creation of the questionnaire's items. The drafted version of this questionnaire and its evaluation form were presented to 5 experts with knowledge and experience in the field of study for them to evaluate the questionnaire for its content validity, inclusion, and linguistic accuracy. The Index of Item Objective Congruence (IOC) from the experts revealed that that the questionnaire had content validity with scores in the range between 2.25-3.00.

The IOC scores and evaluation forms were used to improve the questionnaire which was then used in a try-out. The resulting scores were then analyzed for discrimination in the part of check-list items. The reliability of rating-scale items was calculated using a computer program called SPSS (Statistical Package for the Social Science for Windows) where their discrimination was analyzed through their Standard Deviation (SD) which ranged between $0.2537-2.5380$. The reliability of the questionnaire was assessed using Cronbach's Alpha Coefficient, with a result of 0.8962.

\subsection{Data collection}

The data collection crew was divided into 3 groups in order to distribute the questionnaire collection to cover all areas in the OTOP 2nd City Fair "The Miracle of Thai Wisdom OTOP to the World" at Impact Exhibition Center, Muang Thong Thani, Nonthaburi Province between 17th-25th December 2018 - a total of 9 days. Data was collected by surveying the owners or executives of Small and Medium-sized Enterprises with the designed questionnaire and then verifying the questionnaires' results for completion before analyzing their statistical data by computer.

\subsection{Data analysis}

The data in this research was analyzed by computer using SPSS (Statistical Package for the Social Science for Windows) program, where the data was processed step-by-step. After the questionnaire had been successfully verified, the data obtained was then transcribed into 
numeric codes and saved into the computer by using statistics in order as follows; 1 . Analyze the relationship between the operating conditions of SME manufacturers of the OTOP projects whose products were rated 3-5 stars by using Chi Square $(\chi 2)$ value in Pearson method to analyze the relationship of the variables in the check-list part of the questionnaire.

\section{Results}

From the descriptive statistical analysis, the general conditions of the SME producers in the OTOP Project whose rating was at 3 - 5 star levels were found as follows;

Table 3. Number and percentage of the Small and Medium-sized Enterprises (SMEs) producers of each product category.

\begin{tabular}{|c|c|c|}
\hline Product category & Number & Percentage \\
\hline Food & 52 & 15.76 \\
\hline Beverages & 52 & 15.76 \\
\hline Textiles and Clothing & 75 & 22.73 \\
\hline Household and Decorative items & 54 & 16.36 \\
\hline Artistry items and Gifts & 73 & 22.12 \\
\hline Non-edible herbal products & 24 & 7.27 \\
\hline Total & 330 & 100.00 \\
\hline
\end{tabular}

Most producers' products fell in the category of Textiles and Clothing - accounting for 22.73 percent, followed by Artistry items and Gifts - accounting for 22.12 percent, Household and Decorative items - accounting for 16.36 percent, Food and Beverages accounting for 15.76 percent each, and non-food herbs - representing 7.27 percent, respectively.

It was found that the Chi-square values of the relationship between operating conditions and the rating of OTOP products of Small and Medium-sized Enterprises (SMEs) in Thailand are as follows (Table 4).

From the analysis, it was found there were 19 operating conditions of the SMEproducers in the OTOP program affecting the rating of their 3-5 star products with statistical significance at the .05 level, including; packaging, main target market, marketing promotion, production policy, production plan, standard certifications, raw material management, production methods, product development, production cost, initial investment, working capital, working capital management model, main operational objectives, operational strategy, assignment of duties and responsibilities, employee performance indicators, member remuneration, and member selection.

Table 4. Chi-square values of the relationship between operating conditions and the rating of OTOP products of Small and Medium-sized Enterprises (SMEs).

\begin{tabular}{|c|c|}
\hline $\begin{array}{c}\text { Chi-square values of the relationship between operating } \\
\text { conditions and the rating of OTOP products of Small and } \\
\text { Medium-sized Enterprises (SMEs) }\end{array}$ & P - Value \\
\hline Packaging format & $0.00^{*}$ \\
\hline Main target market & $0.00^{*}$ \\
\hline Marketing promotion & $0.00^{*}$ \\
\hline Production policy & $0.02^{*}$ \\
\hline Production plan & $0.05^{*}$ \\
\hline
\end{tabular}




\begin{tabular}{|c|c|}
\hline Standard certifications & $0.00^{*}$ \\
\hline Raw material management & $0.02^{*}$ \\
\hline Production methods & $0.01^{*}$ \\
\hline Product development & $0.00^{*}$ \\
\hline Production cost & $0.00^{*}$ \\
\hline Initial investment & $0.00^{*}$ \\
\hline Working capital & $0.00^{*}$ \\
\hline Working capital management model & $0.00^{*}$ \\
\hline Operating conditions of Small and Medium-sized Enterprises & $\mathrm{P}-$ Value \\
\hline Main operational objectives & $0.00^{*}$ \\
\hline Operational strategy & $0.03^{*}$ \\
\hline Assignment of duties and responsibilities & $0.01^{*}$ \\
\hline Employee performance indicators & $0.00^{*}$ \\
\hline Member remuneration & $0.03^{*}$ \\
\hline Member selection & $0.03^{*}$ \\
\hline
\end{tabular}

* Statistically significant at the .05 level

\section{Discussion}

From the analysis results, it was found that the Marketing Operating Conditions such as packaging, main target market, and marketing promotion significantly influenced the ranking of 3-5 star OTOP products at the .05 level. This means that if a business has a unique product design and craftsmanship, promotional marketing through communication channels that allow customers more convenience and easier trade, participation in the OTOP fairs to promote their products and increase sales, the use of qualified raw materials in production to make products of high quality - these conditions can lead to having their OTOP products rated 3-5-star at a statistical significance at the .05 level. This might be due to how OTOP products can make customers trust the business's products and Thais prefer to use more Thai-made products. This corresponds to a work of $[4,5]$ which analyzed strengths, weaknesses, opportunities and obstacles of the One Tambon One Product businesses. The results of the study found that the general operating statuses that affected the rating of the products in five product groups of the One Tambon One Product (OTOP) businesses with the statistical significance at the .05 included these 11 factors; main objectives of marketing and manufacturing, business establishment model, business operating period, number members, founding investment amount, capital source, main target market, selling method, estimated monthly average sales, return payment method, and the use of technology in marketing.

This is consistent with a similar study by [6] which explored the operating conditions, problems, and needs of the One Tambon One Product manufacturers in the Food category with a rating between 1-2 stars.

It was found that most of the One Tambon One Product producers produced processed food and operated with consistent production quality control methods and focus network establishing strategies with shops and other manufacturers to exchange marketing information. Most of them were found selling products at local exhibition centers while aiming to develop products to 3-5 star levels. They also created incentives to buy by focusing on ensuring their products' qualities such as taste, quantity, and hygiene. They also continuously improved their products by supporting local production of raw materials 
and putting emphasis on packaging development which required modern machinery in production. These producers wanted the government to pay attention to the manufacturers, thoroughly provide them news and information, and reduce budgeting conditions.

This is also in accordance with a work by [7,8] which studied the management approaches of the One Tambon One Product project of producers whose products were selected as the OTOP champions.

It was found that these producers defined complete and clear details for their required raw materials, developed and improved existing products to be more diverse, built networks to connect with other shops and communities, offered exchange of products, and produced products to higher international standards $[9,10]$. They also used technology in recording trade transactions, analyzed and compared their current raw material prices with the market, developed and improved existing products to be more diverse, developed members within the group through training and the use of computers in the operation, etc.

Therefore, from the research results, entrepreneurs of Small and Medium-sized Enterprises (SMEs) that produce OTOP products should improve and develop more varieties of One Tambon One Product, create a good image of Thai products by developing and improving the production process to be even more standardized, create higher volume production capacity as manufacturing is a critical basis for the survival of various operations, improve packaging or packaging design - which in term increases the value of their products and also helps to extend products' shelf life, and build a network (cluster) of manufacturers to promote the use and development of local resources and wisdom to meet the market's needs.

\section{References}

1. P. Luangpaiboon, Computers and Electronics in Agriculture 135 (2017)

2. K. Natsuda et al, Canadian J. Development Studies 33(3) (2012)

3. K. Nanthasudsawaeng, Guidelines for increasing operational efficiency for entrepreneurs of one tambon one product (OTOP) in Rayong (2020)

4. A.R. Muslim et al, Systematic Reviews in Pharmacy 11(1) (2020)

5. W. Srisorn et al, The EUrASEANs: Journal on Global Socio-Economic Dynamics 4(17) (2019)

6. T. Phimolsathien, International J. of Innovation, Creativity and Change 13(6) (2020)

7. V. Noble, Territory, Politics, Governance 7(4) (2019)

8. D. Ushakov, Actual Problems of Economics 156(6) (2014)

9. D. Ushakov, C. Shieh, Actual Problems of Economics 2(3) (2013)

10. A. Př́vara, Economic Research 33(1) (2020) 